\title{
Erratum to: Relationship Dynamics and Partner Beliefs About Viral Suppression: A Longitudinal Study of Male Couples Livingwith HIV/AIDS (The Duo Project)
}

\author{
Amy A. Conroy ${ }^{1} \cdot$ Kristi E. Gamarel $^{2} \cdot$ Torsten B. Neilands $^{1} \cdot$ Samantha E. Dilworth $^{1}$ \\ Lynae A. Darbes ${ }^{3} \cdot$ Mallory O. Johnson $^{1}$
}

Published online: 4 July 2016

(C) Springer Science+Business Media New York 2016

\section{Erratum to: AIDS Behav \\ DOI 10.1007/s10461-016-1423-9}

Unfortunately, there is an error in Table 2 of the Original publication. In Table 2, the word "unsuppressed" should be replaced with "suppressed" in all three instances of the following statement: "For those who were inaccurate, did they believe partner was unsuppressed?".

The correct Table 2 is given below.

The online version of the original article can be found under doi:10.1007/s10461-016-1423-9.

Amy A. Conroy

amy.conroy@ucsf.edu

1 Department of Medicine, Center for AIDS Prevention Studies, University of California - San Francisco, 550 16th Street 3rd Floor, San Francisco, CA, USA

2 Department of Psychiatry and Human Behavior, Brown University, Providence, RI, USA

3 Department of Health Behavior and Biological Sciences, University of Michigan, Ann Arbor, MI, USA 
Table 2 Viral load test results, partner beliefs, and accurate partner beliefs about viral suppression at three study visits of the Duo Project

\begin{tabular}{|c|c|c|c|}
\hline & Visit 1 & Visit 2 & Visit 3 \\
\hline Total sample $(\mathrm{N})$ & 407 & 319 & 263 \\
\hline Virally suppressed (blood test) (\%) & 49.9 & 51.1 & 49.4 \\
\hline Virally suppressed (partner belief) (\%) & 74.2 & 84.9 & 89.7 \\
\hline Accurate partner belief about viral suppression $(\%)$ & 60.0 & 55.5 & 53.6 \\
\hline For those who were inaccurate, did they believe partner was suppressed? (\%) & 80.4 & 88.0 & 93.4 \\
\hline Seroconcordant couples $(\mathrm{N})$ & 291 & 227 & 192 \\
\hline Virally suppressed (blood test) $(\%)$ & 45.0 & 48.9 & 49.0 \\
\hline Virally suppressed (partner belief) (\%) & 72.9 & 84.1 & 90.1 \\
\hline Accurate partner belief about viral suppression $(\%)$ & 59.8 & 53.3 & 54.7 \\
\hline For those who were inaccurate, did they believe partner was suppressed? (\%) & 84.6 & 87.7 & 95.4 \\
\hline Serodiscordant couples $(\mathrm{N})$ & 116 & 92 & 71 \\
\hline Virally suppressed (blood test) (\%) & 62.1 & 56.5 & 50.7 \\
\hline Virally suppressed (partner belief) (\%) & 77.6 & 87.0 & 88.7 \\
\hline Accurate partner belief about viral suppression (\%) & 60.3 & 60.9 & 50.7 \\
\hline For those who were inaccurate, did they believe partner was suppressed? (\%) & 69.6 & 88.9 & 88.6 \\
\hline
\end{tabular}

